\title{
Neanderthal genome to be unveiled
}

The entire genome of a 38,000-year-old Neanderthal has been sequenced by a team of scientists in Germany. The group is already extracting DNA from other ancient Neanderthal bones and hopes that the genomes will allow an unprecedented comparison between modern humans and their closest evolutionary relative.

The three-year project, which cost about $€ 5$ million (US\$6.4 million), was carried out at the Max Planck Institute for Evolutionary Anthropology in Leipzig. Project leader Svante Pääbo will announce the results of the preliminary genomic analysis at the American Association for the Advancement of Science annual meeting in Chicago, Illinois, which starts on 12 February.

"We are working like crazy at the moment," says Pääbo, adding that his Max Planck colleague, computational biologist Richard Green, is coordinating the analysis of the genome's 3 billion base pairs.

Comparisons with the human genome may uncover evidence of interbreeding between Neanderthals and humans, the genomes of which overlap by more than $99 \%$. They certainly had enough time for fraternization -
Homo sapiens emerged as a separate species by about 400,000 years ago, and Neanderthals became extinct just 30,000 years ago. Their last common ancestor lived about 660,000 years ago, give or take 140,000 years.

The genome may also deliver more details about how these species developed their different physical traits, adapted to their environment and evolved to fight disease.

Despite previous reports that the German group's Neanderthal samples may have been contaminated with DNA from modern humans ${ }^{1}$, an analysis of a Neanderthal mitochondrial genome ${ }^{2}$ has allowed the researchers to largely rule out such contamination. "I have every reason to believe this is going to be authentic Neanderthal sequence," says Edward Rubin, director of the US Joint Genome Institute in Walnut Creek, California, which is also sequencing Neanderthal DNA and has collaborated with the German group in the past ${ }^{3}$.

Almost all of the Neanderthal genome to be unveiled in Chicago comes from DNA extracted from a single bone originally discovered in a cave near Vindija in Croatia.

The age of the sample means that its DNA has degraded into fragments typically only about
$50-60$ base pairs long. But the German group used new sequencing technology, developed by 454 Life Sciences of Branford, Connecticut, that can analyse segments of this length.

The German team has recently extracted DNA from the bones of five other Neanderthals - and so is well on the way to creating a library of Neanderthal genomes that would allow stronger comparisons with modern humans.

Rubin's group is also sequencing Neanderthal DNA from the Croatian bone, and is trying to find other specimens to work on; as are other teams in France and Spain.

Pääbo says that his group will publish a first draft of the entire Neanderthal genome later this year, as a single read of all base pairs. However, some published human genomes had all their base pairs read eight to ten times before publication. The team says that its single-read of the Neanderthal genome is sufficient for publication because the technique used does not rely on the same DNA reassembly process used in conventional 'shotgun' sequencing.

Rex Dalton

$$
\begin{aligned}
& \text { 1. Dalton, R. Nature 449, } 7 \text { (2007). } \\
& \text { 2. Green, R. E. et al. Cell 134, 416-426 (2008). }
\end{aligned}
$$

3. Noonan, J. P. et al. Science 314, 1113-1118 (2006).

\section{GRAPHIC DETAIL Venture capital avoids bloodbath}

\author{
Venture capitalists raised less \\ money and spent less money in \\ 2008 than they did the previous \\ year according to the MoneyTree \\ report, a survey of venture-capital \\ activity released on 24 January. \\ But not everyone emerged a \\ loser. Investment in the fashionable \\ clean-technology sector - \\ encompassing everything from \\ renewable energy to cleaner \\ building materials - swelled by \\ $52 \%$ last year to US\$4.1 billion. \\ "We believe that regardless of \\ how poor the economy is, you're \\ going to see a very strong interest \\ in the 'cleantech' sector over the \\ next several years," says Mark \\ Heesen, president of the National \\ Venture Capital Association \\ (NVCA), based in Arlington, \\ Virginia, which produced \\ the report with consultants
}

\section{PricewaterhouseCooper.}

Biotechnology did not fare as well. Investment in the industry dropped by $14 \%$ to $\$ 4.5$ billion, close to the level of investment it received in 2006. In the fourth quarter - probably a better indication of how the industry will fare in 2009 - investment was $23 \%$ lower than in the fourth quarter of 2007.

Venture capitalists raised $\$ 28.0$ billion for their investment funds in $2008,21.4 \%$ less than in the previous year, and the number of mergers and acquisitions of venture-backed companies declined from 360 to 260 . Only 6 venture-backed companies went public via an initial public offering, compared with 86 in 2007.

This trend may have actually helped young companies, says David

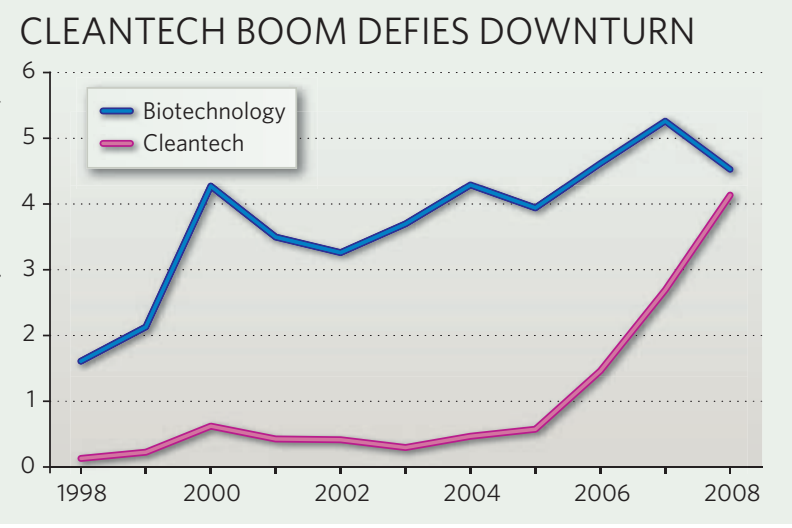

Brophy of the Stephen M. Ross School of Business at the University of Michigan in Ann Arbor, because venture capitalists may turn to earlier-stage deals in the hope that the market will have recovered by the time the companies mature. Last year, the youngest of companies 'seed' companies - received a 19\% boost against the backdrop of an $8 \%$ decrease in total venture-capital investment.
Brophy says that the venturecapital community will probably experience a bigger hit in the coming year. But for some, 2008 was not as painful as expected. "Most were thinking it was going to be a bloodbath, but we didn't see that," says Heesen.

And by today's standards 'not a bloodbath' sounds refreshingly optimistic.

Heidi Ledford 